\title{
Presentation of obstructive left heart malformations in infancy
}

\author{
Majd Abu-Harb, Jonathan Wyllie, Edmund Hey, Sam Richmond, Christopher Wren
}

\begin{abstract}
This study documents the presentation of acutely life threatening congenital heart disease in infancy in order to assess the performance of screening examinations soon after birth and at 6 weeks of age. All cases of obstructive left heart malformations presenting in infancy in one health region from 1987-91 were analysed retrospectively. Altogether, 120 infants presented with either hypoplastic left heart syndrome, interruption of the aortic arch, coarctation of the aorta, or aortic valve stenosis. Twelve became symptomatic or died within 24 hours. Thirty four had an abnormal neonatal examination, eight of whom were referred. Six more became symptomatic before discharge. Ninety four babies went home, 51 developed heart failure before 6 weeks, and another seven died without diagnosis. Twenty five of $36(69 \%)$ reaching 6 weeks without diagnosis had a second examination which was abnormal in 17. Two babies died undiagnosed after 6 weeks and the other 18 presented at up to 11 months of age. The neonatal and 6 week examinations perform poorly as screening tests for congenital heart disease. A normal neonatal examination does not exclude life threatening congenital heart disease.
\end{abstract}

(Arch Dis Child 1994; 71: F179-F183)

Congenital heart malformations are the commonest of all congenital malformations, accounting for $9 \%$ of all infant deaths and $40 \%$ of deaths due to congenital malformations. ${ }^{1}$ While most congenital heart disease is recognised in life in infancy, ${ }^{2}$ some may escape notice until after death ${ }^{1}$ or until later in life. Some infant deaths from unrecognised congenital heart disease result from potentially treatable abnormalities. ${ }^{1}$

It has long been recognised that congenital heart disease may be difficult to diagnose and that earlier recognition may improve the prospects for both survival and treatment. ${ }^{3}$ Screening for congenital heart disease is one of the main reasons for routine examination of babies in the neonatal period and in early infancy. ${ }^{34}$ There has been little prospective assessment of such screening, partly because of the difficulties of ascertainment of false negative cases. Such ascertainment would have to include all cases including those diagnosed only after death, as the aim of screening is to detect all potentially treatable life threatening abnormalities. $^{4}$
Because a previous report from this institution identified four malformations (hypoplastic left heart syndrome, interruption of the aortic arch, coarctation of the aorta, and aortic valve stenosis) as being the most likely to cause death after discharge from hospital ${ }^{1}$ and, because the main purpose of screening should be to detect abnormalities that might present with collapse or sudden death, this study deals only with these four diagnoses.

Its aim is to investigate the presentation of serious, potentially life threatening congenital heart disease and to examine the efficacy of screening examinations undertaken soon after birth and at 6 weeks of age.

\section{Methods}

POPULATION

The Northern Health Region is geographically well defined and has a population of 3076600 . The birth rate is close to 40000 per year and all cases of suspected congenital heart disease from 15 of the 16 health districts are referred to a single paediatric cardiology centre. Patients from the health district of South Cumbria (population 172500) are referred elsewhere for geographical reasons but there is otherwise no outward cross border referral of infants with congenital heart disease. Because of this, South Cumbria has been excluded from this study, which considers the other 15 health districts within the region.

\section{DATA SOURCES}

All cases of obstructive left heart malformation diagnosed in life in infancy were identified from the Northern Regional Fetal Abnormality Survey, which collects data on all serious congenital malformations in fetuses, stillbirths, and liveborn infants, and includes all cases of congenital heart disease diagnosed in infancy. ${ }^{5}$ The Northern Regional Survey of Perinatal, Late Neonatal, and Infant Mortality provided information on all infants with congenital heart disease who died before a cardiological diagnosis was made, and on total infant deaths. ${ }^{6}$ The Office of Population Censuses and Surveys provided data on the regional birth rate.

\section{CASE DEFINITION}

All cases of hypoplastic left heart syndrome, interruption of the aortic arch, coarctation of the aorta, and aortic valve stenosis, diagnosed in infancy from 1987-91 were identified. Hypoplastic left heart syndrome was diagnosed when aortic atresia was associated with an
Corresponde

Accepted 10 August 1994 
Details of age at diagnosis

\begin{tabular}{|c|c|c|c|c|}
\hline & $\begin{array}{l}\text { Hypoplastic left } \\
\text { heart syndrome }\end{array}$ & $\begin{array}{l}\text { Interruption of } \\
\text { the aortic arch }\end{array}$ & $\begin{array}{l}\text { Coarctation } \\
\text { of the aorta }\end{array}$ & $\begin{array}{l}\text { Aortic valve } \\
\text { stenosis }\end{array}$ \\
\hline Diagnosed antenatally & 1 & 1 & 1 & 3 \\
\hline Death within 24 hours & $1 \star$ & 0 & $1^{\star}$ & 0 \\
\hline Presenting within 24 hours & 5 & 4 & 1 & 0 \\
\hline Abnormal neonatal examination & $4: 15(27 \%)$ & $1: 14(7 \%)$ & $10: 46(22 \%)$ & $19: 33(58 \%)$ \\
\hline Diagnosis before discharge & 1 & 7 & 5 & 1 \\
\hline \multicolumn{5}{|l|}{ Death after discharge and before } \\
\hline & 3 & 2 & 2 & 0 \\
\hline \\
\hline Received 6 week examination & 0 & 0 & 6 & 19 \\
\hline Detected at 6 week examination & 0 & 0 & 4 & 13 \\
\hline \multicolumn{4}{|l|}{ Death without diagnosis after } & 2 \\
\hline Diagnosed after 6 weeks & 0 & 0 & 5 & 13 \\
\hline Total cases & 22 & 19 & 49 & 36 \\
\hline Birth prevalence & $1: 9000$ & $1: 10000$ & $1: 4000$ & $1: 5000$ \\
\hline
\end{tabular}

^Other lethal abnormalities.

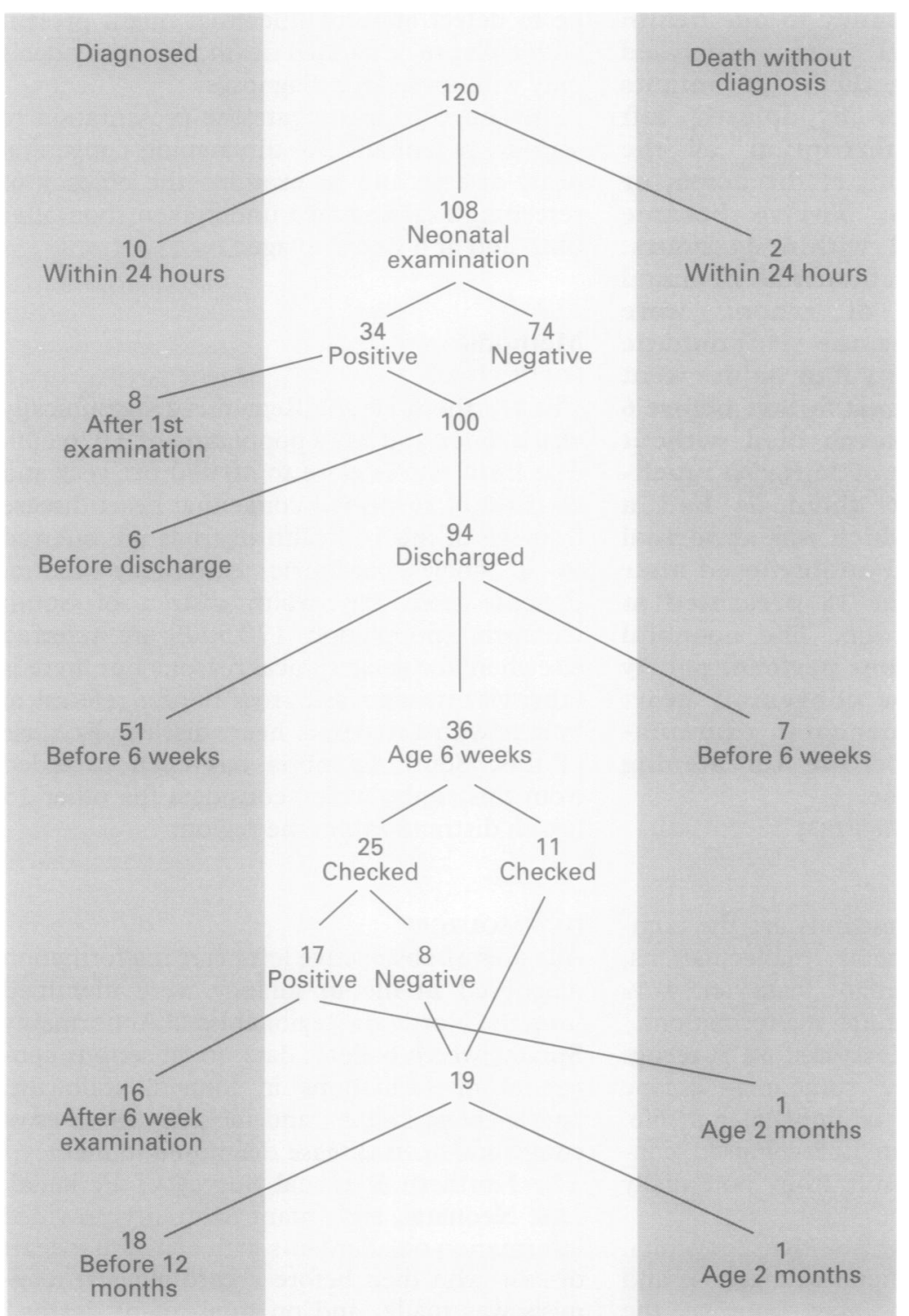

Figure 1 Details of the presentation of 120 babies diagnosed after birth and of the results of examinations performed soon after birth and at 6 weeks of age. Diagnoses in life are shown to the left and those made only after death to the right.

intact ventricular septum, hypoplasia or atresia of the left ventricle, and mitral hypoplasia or atresia. All cases of interruption of the aortic arch were included irrespective of the associated cardiac malformation. All cases of coarctation of the aorta diagnosed in infancy were included, whether isolated or associated with cardiac malformation. All cases of aortic valve stenosis diagnosed in infancy were included, regardless of their severity, but other more complex types of left ventricular outflow obstruction (such as hypertrophic cardiomyopathy and subaortic obstruction in double inlet left ventricle) were excluded.

Details of routine neonatal examinations in all identified cases were obtained by retrospective review of the paediatric cardiology case notes, the neonatal notes from the hospital where the baby had been born, and from the perinatal mortality survey records. The general practitioner and/or health visitor records provided information on all babies who reached the age of 6 weeks without a cardiological diagnosis. Note was made of the time and mode of presentation to the paediatric cardiology unit, the timing, findings, and outcome of the neonatal examination, and the occurrence, timing, findings, and outcome of the 6 week check. Patients were included only if a diagnosis of congenital heart disease was made before the age of 12 months and was confirmed by echocardiography, cardiac catheterisation, surgery, or necropsy. Diagnoses were timed from the date when congenital heart disease was confirmed by a paediatric cardiologist and not from the date when first seen by a paediatrician, whether or not that examination generated a referral to a specialist.

To determine the policy for neonatal examination in the region the on-call senior house officer for paediatrics in each maternity unit was telephoned to inquire about the policy for neonatal examination and predischarge examination and also the purpose of these examinations.

\section{Results}

In the five years of the study, from 1987-91 there were 191701 live births in the 15 health districts (population 2904100 ), and a birth rate of 13.2 per 1000 population per year. In the same period there were 1660 deaths in infancy (an infant mortality rate of 8.7 per 1000 live births) of which 421 (25\%) were due to congenital malformation. In the study period 1009 cases of congenital heart disease were confirmed in infancy, a prevalence of 5.3 per 1000 .

The four types of obstructive left heart malformation were diagnosed in 126 infants, accounting for $12 \cdot 4 \%$ of all congenital heart disease diagnosed in infancy. Antenatal diagnosis was made in six cases (table). Because the diagnosis was made before birth and diagnosis and management did not depend on routine postnatal examination, these cases were excluded from further analysis. The remaining 120 cases will be considered in detail (fig 1).

\section{TIMING OF PRESENTATION}

\section{Before discharge}

All the cases in this study were born in hospital. Twelve babies presented before 24 hours of age, 10 of whom were referred to a cardiologist. One baby died before her cardiac 


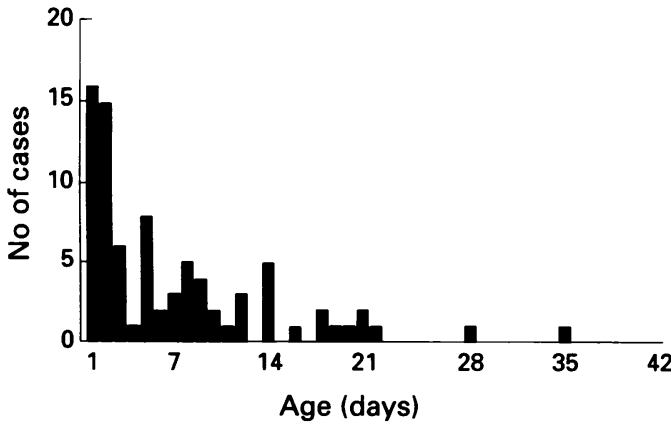

Figure 2 Age in days at the onset of symptoms of heart failure in 81 babies. As can be seen, 78/81 (96\%) developed symptoms by the age of 3 weeks.

abnormality (hypoplastic left heart syndrome) was diagnosed, and a second baby with recognised trisomy 18 died before the presence of his coarctation was recognised.

The remaining 108 babies all had a routine neonatal examination. Abnormalities were found in 34, eight of whom were referred directly. The abnormalities detected were cyanosis in two (both of whom had coarctation of the aorta plus transposition of the great arteries), a murmur plus heart failure in one baby with hypoplastic left heart syndrome, a murmur plus poor pulses in one baby with interruption of the aortic arch, and an isolated heart murmur in the other 30 . A second examination was carried out before discharge for clinical reasons in 13 babies, some of whom had had abnormalities noted on a previous examination. This second examination was abnormal in 11 babies, six of whom were referred before discharge. Of 26 babies sent home despite an abnormal neonatal examination 10 presented with heart failure before 6 weeks, three were referred with a murmur before 6 weeks, and the other 13 were referred after confirmation of the presence of a murmur at the 6 week examination.

\section{After discharge but before 6 weeks of age}

Fifty one babies presented with symptoms and were referred after discharge but before 6 weeks of age. Another seven babies died undiagnosed in the same period, all of whom had had a normal neonatal examination.

\section{After 6 weeks of age}

Twenty five babies, 13 of whom were already known to have a murmur found at the neonatal examination, received a routine examination at 6 weeks of age. These 13, and four other cases, were confirmed to be or found to be abnormal. Abnormalities detected were a systolic murmur in 14 (13 with aortic valve stenosis and one with coarctation of the aorta), a murmur and heart failure in one patient with coarctation, a murmur and poor pulses in another patient with coarctation, and poor pulses alone in one other patient with coarctation of the aorta. All 17 were referred to a paediatric cardiologist, although one baby died suddenly before he could be seen. One other baby, who had not received a 6 week examina- tion died undiagnosed after 6 weeks of age. The remaining 18 babies were referred after detection of a murmur or development of heart failure, the oldest case being referred at 11 months.

\section{ONSET OF SYMPTOMS}

Most of the babies in this study $(81 / 120,68 \%)$ presented with symptoms of heart failure such as breathlessness and poor feeding during the first six weeks of life. Many would have been dependent on patency of the ductus arteriosus for systemic blood flow but, with the exception of those with aortic valve stenosis, would have had few or no signs of heart disease until the duct began to close. The age at onset of symptoms of heart failure for these 81 cases is shown in fig 2.

\section{DIAGNOSTIC CATEGORIES}

\section{Hypoplastic left heart syndrome}

During the five year study period 21 cases of hypoplastic left heart syndrome were diagnosed after birth. One baby died during the first few hours of life and postmortem examination revealed pulmonary lymphangiectasia and hypoplastic left heart syndrome. Five babies became symptomatic and were referred before 24 hours. The remaining 15 received a routine examination within the first two days of life. Abnormal signs were found in four babies, one of whom was referred before discharge from hospital. The other three became symptomatic after discharge and were referred and diagnosed before death. Of the 11 babies with normal neonatal examinations, eight developed symptoms and were referred back to their local hospital although three died shortly afterwards, before a diagnosis had been made. The age of presentation ranged from 1 hour to 18 days (median two days). All presented with symptoms of heart failure, particularly breathlessness and poor feeding. The mortality was $100 \%$ despite surgical treatment being offered to some babies.

\section{Interrupted aortic arch}

Eighteen cases of interrupted aortic arch were diagnosed after birth. Four became symptomatic within the first 24 hours and were referred. The other 14 received a routine neonatal examination. An abnormality was noted in one baby who was referred; six more became symptomatic before discharge and were referred. Seven babies were discharged home and all were later readmitted to hospital with heart failure, although in two of these death occurred before diagnosis. The age at presentation ranged from one to 16 days (median three days). There were 13 deaths among the 18 postnatally diagnosed cases.

\section{Coarctation of the aorta}

Forty eight cases of coarctation of the aorta were diagnosed after birth. The median age at presentation for the whole group was 10 days. 
Twenty three cases had isolated coarctation and 17 of these $(74 \%)$ presented in the first four weeks of life; the remaining 25 had associated congenital heart disease and $22(88 \%)$ presented in the first four weeks. One baby with trisomy 18 died before 24 hours and before his cardiovascular malformation was identified. A second baby became symptomatic and was referred on the first day of life.

A routine neonatal examination was performed in 46 cases. Abnormal signs were detected in 10 (a murmur in eight and cyanosis in two) and five (including both cyanosed babies who also had transposition of the great arteries) were referred before discharge.

Forty one babies were discharged home. Two were readmitted to hospital with heart failure (aged 9 and 18 days) and died soon afterwards, before their cardiac diagnosis was made. Thirty babies were referred within the first four weeks of life, 27 presenting with heart failure. One further baby presented with heart failure at 35 days. Six of the remaining eight babies were examined at 6 weeks of age and four were referred. The last four babies (two who were not thought to have any abnormality at 6 weeks and two who were not checked at 6 weeks) presented with a murmur or heart failure at up to 11 months of age.

\section{Aortic valve stenosis}

Thirty three cases of aortic valve stenosis were diagnosed after birth. All received a routine neonatal examination that was abnormal in 19 , although only one was referred before discharge from hospital. Symptoms developed in five babies soon after discharge and they were referred to a paediatric cardiologist. Only 19 of 27 babies were examined at 6 weeks and abnormalities were noted in 13 , all of whom were then referred. One baby, however, died suddenly at home before his appointment with a cardiologist. One other baby who had not had a 6 week examination died undiagnosed at the age of 2 months. The remaining 13 babies were referred after a murmur was detected by the general practitioner in infancy.

\section{TELEPHONE SURVEY}

The telephone survey showed that it is routine practice to perform an examination on the first day of life in all 16 maternity units in the 15 health districts. In four units it was also routine practice to do a predischarge examination. The commonest reasons given for such examinations were screening for abnormalities (particularly cataracts, congenital heart disease, and dislocated hip), and to reassure the mother.

\section{Discussion}

Screening for asymptomatic disease is widely advocated. 3478 Such screening should only be advised if the disease is detectable with acceptable sensitivity and specificity, and then only if earlier detection is likely to result in an improvement in outcome when compared with symptomatic presentation. ${ }^{34}$ Our data suggest that the routine neonatal and 6 week examinations, as currently practised, do not fulfil the first of these conditions with respect to congenital heart disease.

This study has concentrated on four specific cardiovascular abnormalities because they have been shown to be the main causes of death from congenital heart disease after discharge from hospital and before diagnosis. ${ }^{1}$ It is unlikely that recognition of other types of congenital heart disease would be any more effective given that aortic valve stenosis, in particular, is characterised by a murmur and our data show that $58 \%$ of such babies had an abnormal neonatal examination (but only one was referred).

Intensive screening for congenital cardiovascular malformations has been advocated ${ }^{9} 10$ but the low prevalence in the population, the low sensitivity of the neonatal examination, the low uptake of the 6 week examination, and the fact that our data show that nearly $70 \%$ of cases will have presented before 6 weeks, argue that more intensive screening is unlikely to detect a significant proportion of cases. Furthermore, the variability of age at onset of symptoms, and the rapid deterioration thereafter that is characteristic of the four conditions considered here, make it impossible to suggest more appropriate timings for examinations.

The study shows that the routine neonatal examination of 108 babies with left heart outflow obstruction was abnormal in only 34 (31\%). Of the 94 babies discharged home 58 $(62 \%)$ became symptomatic before the next scheduled examination at 6 weeks, and seven of these died before a cardiac diagnosis was made. Only 25 of the 37 reaching 6 weeks of age received a routine examination, and this was abnormal in only $17(68 \%)$. On 50 occasions abnormalities were noted at the neonatal and/or the 6 week examination, yet on 26 occasions $(52 \%)$ this did not result in a referral.

Three clear conclusions can be drawn from these results. Firstly, routine neonatal examination is not good at detecting left ventricular outflow obstruction. Secondly, babies with these particular cardiovascular abnormalities who are not detected before discharge from hospital usually present with symptoms before the 6 week examination. Thirdly, and perhaps most importantly, when abnormalities are detected the information is often not acted upon.

The neonatal examination has too low a sensitivity ( $31 \%$ in this study) to be of any use as a screening test. We should cease to regard it as anything more than a case finding exercise. Failure to detect an abnormality at the first examination does not mean that the baby is free of serious congenital heart disease. Indeed, of the 74 babies with life threatening heart disease who were passed as normal at the first examination, eight subsequently died before diagnosis.

In this study one baby died without referral to a paediatric cardiologist despite the fact that a murmur had been noted on neonatal examination. Advice on neonatal screening seems to stress (perhaps correctly, though in 
the absence of data) that most murmurs do not signify serious heart disease. ${ }^{37}$ However, the discovery of signs at the neonatal examination may be an indication that the baby does indeed have life threatening heart disease. It is therefore important to have a clear plan about what to do with such babies. Specialist assessment by a paediatric cardiologist is necessary to separate the serious from the trivial or benign. ${ }^{11}$ If this is easily available immediate referral should take place.

Where urgent referral is less easy to arrange the parents should be warned to look out for symptoms of heart failure, such as poor feeding or breathlessness, and should be provided with clear instructions as to whom to contact should the need arise. Furthermore, the baby should be reassessed by a senior paediatrician within a few days of birth and perhaps more than once in the first three weeks of life (see fig 2) in order to detect early signs around the time of duct closure.

We are grateful to the steering groups of the Northern Regional Survey of Perinatal, Neonatal, and Late Infant Mortality and the Northern Regional Fetal Abnormality Survey for access to their data and to the Northern Regional Health Authority (MA-H) and the Sir Jules Thorne Charitable Trust (JPW) for financial support.

1 Abu-Harb M, Hey E, Wren C. Death in infancy from unrecognised heart disease. Arch Dis Child 1994 1994; 71: 3-7.

2 Hoffman JIE, Christianson R. Congenital heart disease in a cohort of 19502 births with long term follow up. Am f Cardiol 1978; 42: 641-7.

3 Hall DMB. Health for all children. A programme for child health surveillance. Oxford: Oxford University Press, 1991 . 4 Donaldson RJ, Donaldson LJ. Essential public health medicine. Dordrecht: Kluwer, 1993.

5 Northern Regional Survey Steering Group. Fetal abnormality: an audit of its recognition and management. Arch Dis Child 1992; 67: 770-4.

6 Northern Regional Health Authority Co-ordinating Group. Perinatal mortality: a continuing collaborative regional survey. $B M \mathcal{F}$ 1984; 288: 1717-20.

7 Valman HB. The first year of life. London: British Medical Association, 1989.

8 Moss GD, Cartlidge PHT, Speidel BD, Chambers TL. Routine examination in the neonatal period. $B M F$ 1991; 302: 878-9.

9 Ward KE, Pryor RW, Matson JR, Razook JD, Thompson WM, Elkins RC. Delayed detection of coarctation in infancy: implications for timing of newborn follow up. Pediatrics 1990; 86: 972-6.

10 Manning DJ. One or two routine neonatal examinations? [letter]. BMF 1991; 302: 1209.

11 Silove ED. Assessment and management of congenital heart disease in the newborn by the district paediatrician. Arch Dis Child 1994; 70: F71-4. 